\title{
Effect of Gender on the Outcomes of ST-Elevation Myocardial Infarction at a Tertiary Care Hospital in Riyadh, Saudi Arabia
}

Mohammed S. Alharbi ${ }^{1}$, Bander K. Alanazi ${ }^{2}$, Ibrahim A. Alquhays ${ }^{3}$, Nawaf A. Alhamied ${ }^{4}$, Abdullah Al Shimemeri ${ }^{5}$

1. Medicine, Qassim University, Buraiydah, SAU 2. Medicine, King Faisal University, Al Ahsa, SAU 3. Internal Medicine, King Faisal University, Al Ahsa, SAU 4. Medicine, King Saud Bin Abdulaziz University for Health Sciences, Riyadh, SAU

5. Internal Medicine: Critical Care, King Saud Bin Abdulaziz University for Health Sciences, Riyadh, SAU

Corresponding author: Mohammed S. Alharbi, mohammedsaadov@gmail.com

\section{Abstract}

\section{Objective}

This study aimed to evaluate the impact of gender on the outcomes among ST elevation myocardial infarction patients at King Abdulaziz Medical City in Riyadh, Saudi Arabia.

\section{Methods}

This retrospective study analyzed the data of 900 patients (770 males and 130 females) admitted between January 2016 and December 2018 diagnosed with ST-elevation myocardial infarction (STEMI). We recorded the baseline characteristics, comorbidities, treatment, complications, and mortality for all patients, and compared these data between female and male patients.

\section{Results}

The baseline characteristics: $\mathrm{BMI}$ and age were higher in females and were statistically significant $(\mathrm{p}=$ 0.0001 ). We found a higher incidence of heart failure in females than in males which was statistically significant $(p=0.0010)$. In addition, the mortality rate was higher in female than in male patients, although this difference was not statistically significant $(\mathrm{p}=0.3850)$.

\section{Conclusion}

In conclusion, despite the advances in the technology and the use of novel reperfusion therapies females were associated with poorer outcomes after adjustment of the baseline characteristics and risk factors. In other words, heart failure, mitral regurgitation, and arrhythmias were higher in females with significant $\mathrm{p}$ values.

Received 07/23/2020

Review began 07/28/2020 Review ended 08/23/2020 Published 08/29/2020

(c) Copyright 2020

Alharbi et al. This is an open access article distributed under the terms of the Creative Commons Attribution License CC-BY 4.0., which permits unrestricted use, distribution, and reproduction in any medium, provided the original author and source are credited.
Categories: Cardiac/Thoracic/Vascular Surgery, Cardiology, Internal Medicine

Keywords: st elevation myocardial infarction, myocardial reperfusion, complications

\section{Introduction}

Globally, around 3 million people sustain ST-elevation myocardial infarction (STEMI) annually, while around 4 million people suffer from non-ST elevation myocardial infarction (NSTEMI) [1]. The rate of STEMI in men is twice as high as that in women [2]. Continuous advancements in reperfusion therapy have resulted in a significant decline in the mortality and related complications in patients with STEMI [3,4]. Multiple studies have investigated the risk factors of mortality, complications, and prognostic factors after STEMI and the results in some studies showed that female gender may adversely affect the clinical outcome in STEMI and it is associated with higher mortality and more complications [5,6]. While the others attributed the difference in the baseline characteristics to be the main reason beyond the poorer outcome rather than the gender itself $[7,8]$.

The structure of the left ventricle differs between the genders, and females are more prone to heart failure due to concentric remodeling despite preserved LV ejection fractions $[9,10]$. Women show a higher incidence of mechanical failures, such as mitral regurgitation and ventricular septal rupture [11]. In most studies, female patients with STEMI also had a higher age and concurrent disease burden, such as diabetes, hypertension, etc., than males [5,6,12,13].

It is not clearly understood whether left ventricular systolic dysfunction after myocardial infarction is responsible for the poorer clinical outcomes and higher rates of complications in women [14]. 
However, other studies did not find a correlation between gender and clinical outcome, they attributed the higher mortality in female patients to a higher age and Killip class at the time of admission, other concurrent diseases, and confounding factors $[11,13,15]$. The health status of female patients at the time of myocardial infarction has also been found to affect the outcomes [16].

Few recent studies have studied gender differences that may affect the prognosis after STEMI in female patients in details. Given the ambiguity in the literature, we need to understand gender-based variations so that tailored therapeutic approaches can be designed. Further, in view of the financial and socio-economic burden of myocardial infarction and coronary disease, it is important to study the mechanisms and the underlying causes that affect clinical outcomes in women. This study aimed to evaluate the impact of gender on the outcomes among ST elevation myocardial infarction patients at King Abdulaziz Medical City in Riyadh, Saudi Arabia.

\section{Materials And Methods}

This study was approved by the ethics committee of King Abdullah International Medical Research Center (No. RSS19/038/R) and conformed to the ethical principles outlined in the Declaration of Helsinki. We performed a retrospective chart review of all adult patients $(n=900)$ with a final diagnosis of STEMI admitted to King Abdulaziz Medical City, Riyadh, Saudi Arabia, between January 2016 and December 2018.

We extracted the following data from the hospital's BestCare database using a customized data collection sheet: demographic data such as age, gender, nationality, height, weight, body mass index (BMI). Moreover, data regarding comorbidities such as hypertension, hyperlipidemia, and diabetes were collected as well as risk factors such as the history of smoking, renal failure, chronic obstructive pulmonary disease, and stroke. We also recorded the cardiac troponins, creatine kinase (CK), CK-MB isoenzyme, electrocardiography (ECG) findings, and echocardiographic data which included: left ventricular ejection fraction (LVEF), significant mitral regurgitation, and any other post-myocardial infarction abnormalities. We further noted the details of treatment, such as coronary artery bypass graft, percutaneous coronary intervention, intravenous fibrinolysis, and angioplasty.

\section{Statistical analysis}

We summarized categorical variables as number (percentage) and numerical variables (continuous variables) as mean and standard deviation (SD). The normality assumptions were assessed for all numerical variables using statistical test. We compared categorical variables using the chi square or Fisher exact test, normally distributed numerical variables with the $t$ test, and other quantitative variables with the Mann-Whitney $U$ test. The differences in baseline characteristics between the genders are expected in the observational studies.

For the adjustment of these differences, a propensity score was generated for the age, BMI, conservative management, diabetes mellitus (DM), hypertension (HTN), dyslipidemia, renal failure and stroke.

Multivariate logistic regression was used to find out the relationship between gender and the different complications considered in this study, adjusting for the generated propensity score. The odds ratios (OR) and estimates with the $95 \%$ confidence intervals (CI) were reported for the associations. We assessed model fit using the Hosmer-Lemeshow goodness-of-fit test. We considered a P-value of $<0.05$ statistically significant and used SAS ${ }^{\circledR}$ software, version 9.4 (SAS Institute Inc., Cary, NC, USA) for all statistical analyses.

\section{Results}

The data of 900 patients with STEMI - 770 males and 130 females - were analyzed. Females had a higher mean age; $65.7 \pm 13.5$ for females vs. $58.9 \pm 12.8$ years for males $(\mathrm{p}=0.0001)$ and BMI was higher in females compared to males and the results were statistically significant $(\mathrm{p}=0.0001)$ as shown in Table 1 . The baseline treatment provided to male and female patients with STEMI is shown in Table 2. No statistically significant differences were observed in the treatment provided except for the conservative line of treatment $(\mathrm{p}=0.0308)$. Table 3 presents the results of the statistical analysis for the risk factors for STEMI among male and female patients. 


\section{Cureus}

\begin{tabular}{|c|c|c|c|}
\hline Variables & Male $(n=770) 85.55 \%$ & Female $(n=130) 14.44 \%$ & p-value \\
\hline Age mean \pm S.D. & $58.9 \pm 12.8$ & $65.7 \pm 13.5$ & 0.0001 \\
\hline Body mass index (BMI) & $28.3 \pm 5.8$ & $30.5 \pm 6.4$ & 0.0001 \\
\hline
\end{tabular}

TABLE 1: Age and body mass index of patients with STEMI.

STEMI: ST-elevation myocardial infarction

\begin{tabular}{|c|c|c|c|}
\hline Baseline treatment & Male & Female & p-value \\
\hline Percutaneous coronary intervention (PCI) & $660(85.7 \%)$ & $107(82.3 \%)$ & $0.1911^{\wedge \wedge}$ \\
\hline Thrombolysis & $78(10.1 \%)$ & $11(8.5 \%)$ & $0.5326^{\wedge} \wedge$ \\
\hline Coronary artery bypass surgery (CABG) & 72 (9.4\%) & $8(6.2 \%)$ & $0.2257^{\wedge} \wedge$ \\
\hline Conservative management & $48(6.2 \%)$ & $15(11.5 \%)$ & $0.0308^{\wedge \wedge}$ \\
\hline
\end{tabular}

TABLE 2: Baseline treatment provided to the patients.

$\wedge$ Chi-Square Test; ${ }^{\wedge} \wedge$ Fisher's Exact Test.

\begin{tabular}{|c|c|c|c|}
\hline Risk factors & Male $(\mathrm{N}=770)$ & Female $(\mathrm{N}=130)$ & p-value \\
\hline Diabetes mellitus & 449 (58.3\%) & $104(79.8 \%)$ & $0.0001^{\wedge}$ \\
\hline Hypertension & $417(54.1 \%)$ & $104(79.8 \%)$ & $0.0001^{\wedge}$ \\
\hline Dyslipidemia & $472(61.2 \%)$ & $92(70.5 \%)$ & $0.0103^{\wedge}$ \\
\hline Previous ischemic heart disease & $159(20.6 \%)$ & $23(17.6 \%)$ & $0.0726^{\wedge}$ \\
\hline Family history & $33(4.2 \%)$ & $8(5.8 \%)$ & $0.1293^{\wedge}$ \\
\hline Smoking & $373(48.4 \%)$ & $12(8.0 \%)$ & $0.0001 \wedge$ \\
\hline Renal failure & $73(9.5 \%)$ & $19(14.6 \%)$ & $0.0267^{n}$ \\
\hline Chronic obstructive pulmonary disease & $14(1.8 \%)$ & $3(2.3 \%)$ & $0.2344^{\wedge \wedge}$ \\
\hline Stroke & 46 (6.0\%) & 12 (9.2\%) & $0.0575^{\wedge}$ \\
\hline
\end{tabular}

TABLE 3: Risk factors for complications in STEMI in male and female gender.

$\wedge$ Chi-Square Test; $\wedge^{\wedge}$ Fisher's Exact Test.

STEMI: ST-elevation myocardial infarction

The complications observed in the two groups are shown in Table 4. Heart failure was the most common complication in both genders, but its frequency was higher in females than in males with 54 (41.5\%) compared to $280(27 \%)$ with significant $p$-value $(p=0.0010)$. Mitral regurgitation was the second most frequent complication in both genders, occurring in 41 (31.5\%) of females and $169(21.9 \%)$ of males $(\mathrm{p}=$ 0.0201). Arrhythmias were diagnosed in 36 (27.7\%) of females and $158(20.5 \%)$ in males ( $\mathrm{p}=0.768)$. Mortality was higher in females than males 13 (10\%) vs. 59 (7.7\%), but this difference was not statistically 


\section{Cureus}

significant $(\mathrm{p}=0.3850)$.

\begin{tabular}{|c|c|c|c|c|c|c|}
\hline Complications & Male $(\mathrm{N}=770)$ & Female $(N=130)$ & p-value & $\mathrm{aOR}$ & $9 \% \mathrm{Cl}$ & p-value \\
\hline Heart failure & $208(27.0 \%)$ & 54 (41.5\%) & $0.0010^{\wedge \wedge}$ & 1.73 & $(1.149,2.590)$ & $0.0085^{\$}$ \\
\hline Mitral regurgitation & $169(21.9 \%)$ & $41(31.5 \%)$ & $0.0201^{\wedge \Lambda}$ & 1.34 & $(0.874,2.081)$ & 0.175 \\
\hline Tricuspid regurgitation & $232(30.1 \%)$ & $41(31.5 \%)$ & $0.8609^{\wedge}$ & 1.03 & $(0.678,1.577)$ & 0.875 \\
\hline Arrhythmia & $158(20.5 \%)$ & $36(27.7 \%)$ & $0.0768^{\wedge \lambda}$ & 1.48 & $(0.951,2.328)$ & 0.081 \\
\hline Cardiac arrest & 104 (13.5\%) & $20(15.4 \%)$ & $0.6009^{\wedge \wedge}$ & 1.25 & $(0.727,2.175)$ & 0.411 \\
\hline Cardiogenic shock & $78(10.1 \%)$ & $14(10.8 \%)$ & $0.8610^{\wedge \lambda}$ & 1.23 & $(0.660,2.321)$ & 0.506 \\
\hline Died & $59(7.7 \%)$ & $13(10 \%)$ & $0.3850^{\text {^A }}$ & 1.16 & $(0.596,2.290)$ & 0.651 \\
\hline Heart block & $57(7.4 \%)$ & $8(6.2 \%)$ & $0.5907^{\wedge \wedge}$ & 0.69 & $(0.316,1.522)$ & 0.362 \\
\hline \multicolumn{7}{|c|}{ TABLE 4: Complications } \\
\hline \multicolumn{7}{|c|}{$\begin{array}{l}\text {-Denominator of the percentage is the total number of patients. }{ }^{\wedge}{ }^{\wedge} C h i-s q u a r e ~ t e s t /{ }^{\star} \text { Fisher Exact test is used to calculate the } \mathrm{P} \text {-value. } \$ \text { Propensit } \\
\text { score adjusted Logistic regression is used to calculate Odds ratio and } p \text {-value. aOR* Adjusted Odds ratio. Male subjects are considered as } \\
\text { reference category. }\end{array}$} \\
\hline
\end{tabular}

\section{Discussion}

Only a few studies have tried to explain the higher mortality in female patients with STEMI as compared to male patients [17-19]. The potential reasons suggested by these authors included a delayed response, differences in the medical attention given to female patients as compared to male patients, or in distinct pathophysiological processes related to the female gender [17]. In our study, we did not find a statistically significant difference in the mortality between the genders, although females had a higher mortality risk than male patients. As described in previous studies, the women in our study had a higher mean age at the time of presentation than men $[18,19]$. Heart failure was more frequent in female than in male patients. Male patients showed higher levels of myocardial injury marker proteins in the blood, such as CK, CK-MB, and troponin C type I. The frequency of previous coronary interventions and findings on ECG did not significantly differ between the genders.

Similar to other studies, risk factors such as hypertension, diabetes mellitus, and dyslipidemia were more prevalent in females $[5,6,12,13]$. This higher risk profile might be the cause of the higher incidence rate of complications after STEMI such as heart failure, mitral regurgitation, arrhythmias, and death in females. We believe this is more likely than gender itself being an independent prognostic factor.

The findings in our study are consistent with those of Ng and Lansky [19], Pedersen et al. [20], and, more recently Kanic et al. [21] who also found a correlation between higher age and more frequent comorbidities in women. Females in our study were older than males at the time of diagnosis, which carries a higher risk of comorbidities. The cardio-protective effect of estrogen before menopause is thought to be the cause of this observation [15]. Even though higher rates of smoking have been reported in males, the mortality rate is higher in females $[11,14]$.

In our study, the treatment modalities were similar in both groups except that conservative management was more frequent in females. The high incidence of mitral regurgitation that we found in female patients was also documented by other authors [16]. The significant difference in the incidence of heart failure in our study with $41.5 \%$ in females as compared to $27 \%$ in males is often attributed to structural differences between the genders [17-20].

\section{Study limitations}

As the study design was retrospective in character, the time elapsed between the start of symptoms and beginning of treatment in our patients could not be determined. Moreover, the results of the study is based on one center thus we could not collect a larger sample.

\section{Conclusions}

In conclusion, despite the advances in the technology and the use of novel reperfusion therapies, females 
were associated with poorer outcomes after adjustment of the baseline characteristics and risk factors. In other words, heart failure, mitral regurgitation, and arrhythmias were higher in females with significant $\mathrm{p}$ values. Further studies are needed to support the results of this research as it was a single center study.

\section{Additional Information \\ Disclosures}

Human subjects: Consent was obtained by all participants in this study. King Abdullah International Medical Research Center issued approval (RSS19/038/R). After reviewing your submitted research proposal and related documents, the IRB has approved the submission. Animal subjects: All authors have confirmed that this study did not involve animal subjects or tissue. Conflicts of interest: In compliance with the ICMJE uniform disclosure form, all authors declare the following: Payment/services info: All authors have declared that no financial support was received from any organization for the submitted work. Financial relationships: All authors have declared that they have no financial relationships at present or within the previous three years with any organizations that might have an interest in the submitted work. Other relationships: All authors have declared that there are no other relationships or activities that could appear to have influenced the submitted work.

\section{Acknowledgements}

Ramesh Kumar, PhD. Department of Biostatistics, King Abdullah International Medical Research Center (KAIMRC). We appreciate (https://www.editage.com) for their participation in English language editing.

\section{References}

1. White HD, Chew DP: Acute myocardial infarction. Lancet. 2008, 372:570-584. 10.1016/s01406736(08)61237-4

2. O'Gara PT, Kushner FG, Ascheim DD, et al.: 2013 ACCF/AHA guideline for the management of ST-elevation myocardial infarction: a report of the American College of Cardiology Foundation/American Heart Association Task Force on Practice Guidelines. Circulation. 2013, 127:362-425. 10.1161/CIR.0b013e3182742cf6

3. Fox KA, Steg PG, Eagle KA, et al.: Decline in rates of death and heart failure in acute coronary syndromes, 1999-2006. JAMA. 2007, 297:1892-1900. 10.1001/jama.297.17.1892

4. Yeh RW, Sidney S, Chandra M, Sorel M, Selby JV, Go AS: Population trends in the incidence and outcomes of acute myocardial infarction. N Engl J Med. 2010, 362:2155-2165. 10.1056/NEJMoa0908610

5. Velders MA, Boden H, van Boven AJ, et al.: Influence of gender on ischemic times and outcomes after STelevation myocardial infarction. Am J Cardiol. 2013, 111:312-318. 10.1016/j.amjcard.2012.10.007

6. Zhang B, Zhang W, Huang RC, et al.: Gender disparity in early death after ST-elevation myocardial infarction. Chin Med J. 2013, 126:3481-3485.

7. Corrada E, Ferrante G, Mazzali C, Barbieri P, Merlino L, Merlini P, Presbitero P: Eleven-year trends in gender differences of treatments and mortality in ST-elevation acute myocardial infarction in Northern Italy, 2000 to 2010. Am J Cardiol. 2014, 114:336-341. 10.1016/j.amjcard.2014.05.007

8. Lanaro E, Caixeta A, Soares JA, et al.: Influence of gender on the risk of death and adverse events in patients with acute myocardial infarction undergoing pharmacoinvasive strategy. J Thromb Thrombolysis. 2014, 38:510-516. 10.1007/s11239-014-1072-7

9. Piro M, Della Bona R, Abbate A, Biasucci LM, Crea F: Sex-related differences in myocardial remodeling. J Am Coll Cardiol. 2010, 55:1057-1065. 10.1016/j.jacc.2009.09.065

10. Melenovsky V, Borlaug BA, Rosen B, et al.: Cardiovascular features of heart failure with preserved ejection fraction versus nonfailing hypertensive left ventricular hypertrophy in the urban Baltimore community: the role of atrial remodeling/dysfunction. J Am Coll Cardiol. 2007, 49:198-207. 10.1016/j.jacc.2006.08.050

11. Ghaffari S, Pourafkari L, Tajlil A, Bahmani-Oskoui R, Nader ND: Is female gender associated with worse outcome after ST elevation myocardial infarction?. Indian Heart J. 2017, 69:28-33. 10.1016/j.ihj.2016.12.003

12. Kyto V, Sipila J, Rautava P: Gender, age and risk of ST segment elevation myocardial infarction . Eur J Clin Invest. 2014, 44:902-909. 10.1111/eci.12321

13. Lawesson SS, Alfredsson J, Fredrikson M, Swahn E: A gender perspective on short- and long term mortality in ST-elevation myocardial infarction - a report from the SWEDEHEART register. Int J Cardiol. 2013, 168:1041-1047. 10.1016/j.ijcard.2012.10.028

14. Scantlebury DC, Borlaug BA: Why are women more likely than men to develop heart failure with preserved ejection fraction?. Curr Opin Cardiol. 2011, 26:562-568. 10.1097/hco.0b013e32834b7faf

15. Leurent G, Garlantezec R, Auffret V, et al.: Gender differences in presentation, management and inhospital outcome in patients with ST-segment elevation myocardial infarction: data from 5000 patients included in the ORBI prospective French regional registry. Arch Cardiovasc Dis. 2014, 107:291-298. 10.1016/j.acvd.2014.04.005

16. Dreyer RP, Smolderen KG, Strait KM, et al.: Gender differences in pre-event health status of young patients with acute myocardial infarction: a VIRGO study analysis. Eur Heart J Acute Cardiovasc Care. 2016, 5:43-54. $10.1177 / 2048872615568967$

17. Bugiardini R, Ricci B, Cenko E, et al.: Delayed care and mortality among women and men with myocardial infarction. J Am Heart Assoc. 2017, 6:005968. 10.1161/JAHA.117.005968

18. Smilowitz NR, Mahajan AM, Roe MT, Hellkamp AS, Chiswell K, Gulati M, Reynolds HR: Mortality of myocardial infarction by sex, age, and obstructive coronary artery disease status in the ACTION RegistryGWTG (Acute Coronary Treatment and Intervention Outcomes Network Registry-Get with the Guidelines). Circulation Cardiovasc Qual Outcomes. 2017, 10:003443. 10.1161/circoutcomes.116.003443 


\section{Cureus}

19. Ng VG, Lansky AJ: Controversies in the treatment of women with ST-segment elevation myocardial infarction. Interv Cardiol Clin. 2016, 5:523-532. 10.1016/j.iccl.2016.06.014

20. Pedersen LR, Frestad D, Michelsen MM, Mygind ND, Rasmusen H, Suhrs HE, Prescott E: Risk factors for myocardial infarction in women and men: a review of the current literature. Curr Pharm Des. 2016, 22:38353852. 10.2174/1381612822666160309115318

21. Kanic V, Suran D, Krajnc I, Kompara G: ST-elevation myocardial infarction in a real world population - An observational retrospective study with a sex perspective. Eur J Intern Med. 2019, 66:81-84.

10.1016/j.ejim.2019.06.004 